\title{
A REVIEW OF ELEMENTS FOR ASSESSMENT OFE-LEARNING READINESS IN LIBYA UNIVERSITIES
}

\author{
Mohamed Munser Saleh ${ }^{1}$, Fauziah Abdul Wahid ${ }^{2}$ \\ Faculty of Science and Technology, University Sains Islam Malaysia (USIM) \\ Bandar Baru Nilai, 71800 Nilai, Negeri Sembilan,Malaysia \\ Corresponding author:mo_mon53@yahoo.com
}

\begin{abstract}
The e-learning is developing rapidly in the world nowadays, where technology has replaced the traditional educational approach in many universities around the world. This is because e-learning can save time and cost in educational approach as a whole. This phenomenon has spread to many developing countries like Libya with the main aim to improve the educational system. However, there seems to be lack of study on the readiness of implementing e-learning in Libya universities. Therefore, this paper will shed some light on elements needed to be evaluated to study the e-learning implementation readiness in Libya universities.
\end{abstract}

Keyword: E-learning; E-learning readiness; Libya University.

\section{Council for Innovative Research}

Peer Review Research Publishing System

Journal: INTERNATIONAL JOURNAL OF COMPUTERS \& TECHNOLOGY

Vol 14 . No. 4

www.ijctonline.com, editorijctonline@gmail.com 


\section{Introduction}

E-learning is developing rapidly in the world nowadays, where technology has replaced the traditional educational approach in many universities around the world. E-learning is a computer-based education delivered online via the Internet or Intranet/Extranet (LAN/WAN)(Dublin, 2003).It refers to a wide range of applications and processes, for example, virtual classroom, digital collaboration and others (Singh et al., 2003). E-learning started to develop progressively in numerous nations because it has high potential in serving the needs to provide education for all types of citizens (UNESCO, 2006). This is because e-learning can save time and cost in educational approach as a whole. This phenomenon has spread to many developing countries like Libya with the main aim to improve the educational system. According to Rhema \& Miliszewska (2011), Libya is currently planning to improve the educational sector in order to widen the opportunities to obtain education among its cuitizen. However, there seems to be lack of study on the readiness of implementing e-learning in Libya universities. Therefore, this paper will shed some light on elements needed to be evaluated to study the e-learning implementation readiness in Libya universities.

\section{E-Learning Readiness Evaluation}

\subsection{E-learning Readiness Model}

Darab and Montazer (2011) have studied the evaluation of e-learning readiness in Iranian universities. They have proposed a proper framework for strengthening the existing capabilities and identifying possible deficits in e-learning implementation. In their study, they employed a detailed survey and analysis in order to come up with a model for elearning readiness. Their model was divided into two categories; educational process readiness and educational product readiness. As for this paper, concentration will be given on educational process readiness that involves six elements namely; content, regulations, financial, human resource, culture and security. This category was chosen because universities in Libya are at the beginning level to employ e-learning and through this paper, it can outline elements that need to be evaluated to determine the readiness of all parties involved in the e-learning implementation.

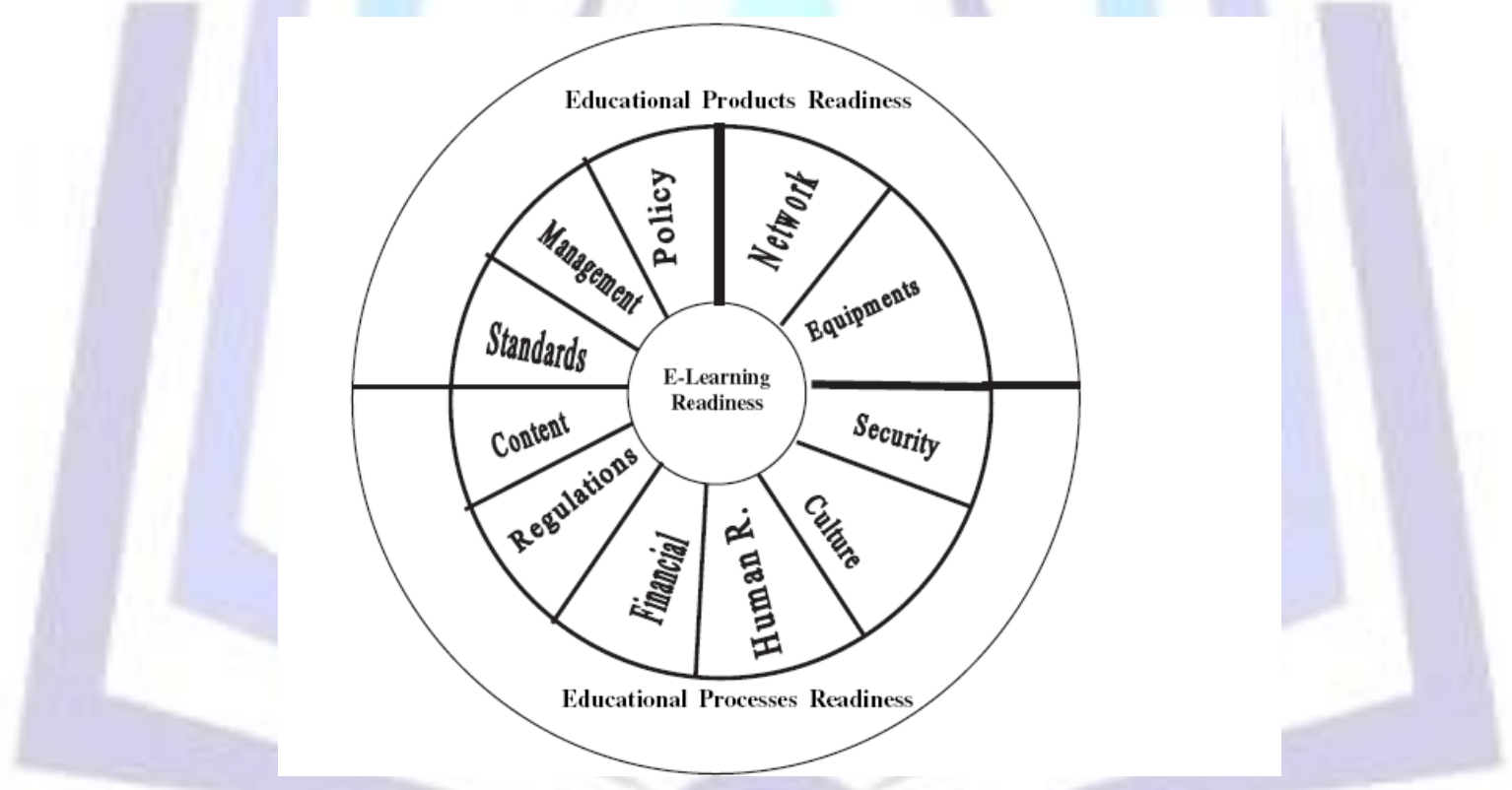

Figure 1: E-learning Readiness Model (Darab \& Montazer, 2011)

\subsection{E-learning Readiness Elements}

This section will analyze the category of educational process readiness in the e-learning readiness model. There are six elements outlined for this category, which are content, regulations, financial, human resource, culture and security.

\subsubsection{Content}

Students often face many problems and challenges during the implementation of e-learning activities, for example, difficulty to access the online information appropriately. In relation to this matter, students need to be given appropriate trainings related to e-learning for them to be able to participate successfully in the process (Smedley, 2012). It must be taken into consideration that not all students have experience using technology, especially Internet. Therefore, trainings need to be given from time to time to expose them to this technology.

\subsubsection{Regulations}

Universities should be ready to adopt e-learning systems to improve learning as well as to gain competitive advantage (Wannemacher, 2006). But, before that, a university needs to outline detail regulations regarding e-learning in order to protect the university as a whole. Among the regulations outline by Darab \& Montazer (2011) is copyright protection 


\section{ISSN 2277-3061}

system for the electronic content (intellectual property protection) and code of documents evaluation (validity guarantee) of electronic education courses (at the university and the ministry levels).

\subsubsection{Financial}

The execution of the e-learning innovation in higher training organizations raised the money related dilemma. The budgetary issue incorporates the upkeep operations and the advancement of the correct gear. These issues push the foundations to discover sufficient assets to accomplish that and to give static specialized backing (Levine \& Sun, 2002). A through audit involving financial needs is compulsory to be conducted before any university aim to venture into e-learning. This is due to the fact that e-learning involves a large sum of money to be implemented.

\subsubsection{Human Resource}

There are various human resource roles whosupported the technology-based environment, but the role of the lecturer is the most important in designing the e-learning environment. This is because the e-learning facilitate great interaction and collaboration between the lecturer and their students during the learning process. This shows that the role of the lecturer as the most influential in developing and delivering the ideas through the e-learning process (Maor, 2003). Hence, lectures need to be well-prepared with knowledge in technology involving the Internet so that they can fully utilize e-learning with their students. This can be done by giving appropriate trainings related to e-learning to lecturers from time to time.

\subsubsection{Culture}

There is other challenges face the e-learning technology, supporting of the traditional teaching model by some of the academic staff. Those staff has skepticism about the success of e-learning, and they believe e-learning can't achieve the required quality, and the other issues such as increase the workload and it causes loss of control.According to Ceri (2005), there are numerous prerequisites to attain the fruitful of executing the e-learning in the organizations, these necessities could be spoken to in changing numerous hierarchical administers inside foundations which incorporate the staff authoritative mix, adaptable conveyance to scholars "on/off facilities", and new ideas of instructing.

\subsubsection{Security}

Secure environment of e-learning requires avoiding four types of threat, or attack, which is manufacturing, modification, interruption and interception. Then, recommends an authentication process in order to determine the process of user legal liability, where this ill will overcomes the illegal use of the e-learning application (Saxena, 2004). Information security is the protection of information from threats and attack.It is implemented in order to ensure e-learning continuity and to accordingly minimize risk and damages.

\section{Conclusion and Future Work}

It can be concluded that there are vital elements that need to be analyze in order to evaluatee-learning process readiness in Libya universities, which is based on Darab and Montazer (2011) model. These elements are content, regulations, financial, human resource, culture and security.E-learning is the best solution to keep up with the development in the education world. It can be observed in recent years that most countries in the world are interested in this approach of education. However, thorough assessment needs to be conducted before implementing e-learning, especially in higher learning institutions. Readiness assessment allows institutions to design systems and put in place appropriate measures that are required for e-learning success.

\section{References}

[1] Ceri\& Organisation for Co-Operation and Development (2005). E-learning in tertiary education:Where do we stand? Education and skills. (France:OECD)

[2] Dublin, L. (2003). If you only look under the street lamps or nine e-learning myths. The E-learning Developers Journal. Retrieved from http://www. eLearningguild.com

[3]B. Darab \&Gh.A. Montazer (2011). An eclectic model for assessing e-learning readiness in the Iranian universities. Computers and Education, 56(2011), 900-910.

[4] Levine, A. \& Sun, J. (2002). Barriers to distance education. Retrieved fromhttp://www.acenet.edu/bookstore/pdf/distributed-learning/distributed-learning-06.pdf

[5]Maor, D. (2003). The teacher's role in developing interaction and reflection in an online learning community. Education Media International,40(1), 127-136.

[6]Rhema, A., \& Miliszewska, I. (2011). Reflections on a trial implementation of an e-learning solution in a libyan university. Issues in Informing Science and Information Technology, 8, 61-76.

[7]Saxena, R. (2004), Security and online content management: balancing access and security, Breaking boundaries: integration and interoperability.Paper presented at the 12thBiennial VALA Conference and Exhibition Victorian Association for Library Automation. 


\section{ISSN 2277-3061}

[8]Singh, G., O' Donoghue, J. \& Worton, H. (2003). A study into the effects of e-learning on higher education. JUTLP, 2(1). Retrieved from http://jutlp.uow.edu.au/2005 v02 i01/odonoghue003.html

[9]Smedley, J. (2012). Implementing e-learning in the Jordanian Higher Education System: Factors affecting impact Ahmad Al-adwan Cardiff Metropolitan University, Wales, UK. International Journal of Education and Development Using Information and Communication Technology, 8(1), 121-135.

[10]UNESCO (2006). Teachers and educational quality: Monitoring global needs for 2015. Retrieved fromhttp://www.uis.unesco.org/TEMPATE/pdf/ Teachers2006/TeachersReport.pdf

[11] Wannemacher, K. (2006). Functional differentiation of incentives for e-teaching at universities. Current Developments in Technology-Assisted Education, 72-76.

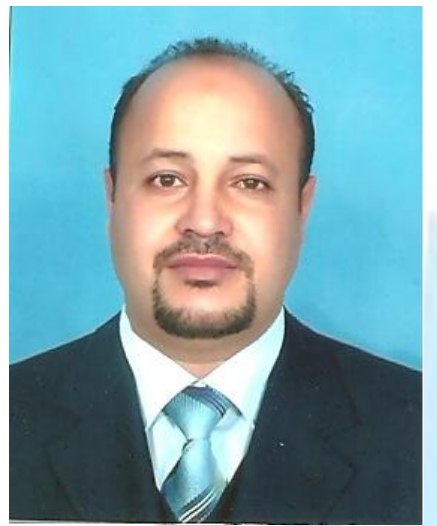

Mohamed Munser Saleh Mansour, was born on 1976 in libya. He is Libyan. He previously was a student of High Institute for preparation of Trainers in Zleettin and graduated in 1997 from Electronic Engineering Division \Computer. He was the head of graduated student unit at the Higher Institute for Comprehensive Alqrhbolli careers in the period (2004-2007). Also he was the head of the department of students activity and trainer at the Higher Institute for Comprehensive Alqrhbolli careers in the period (20082012). He is at present a Master student of Universiti Sains Islam Malaysia (USIM) majoring in Computer Science / Information Security and Assurance (ISA). 